Testing the law of one price in retail banking: an analysis for Colombia using a pair-wise approach

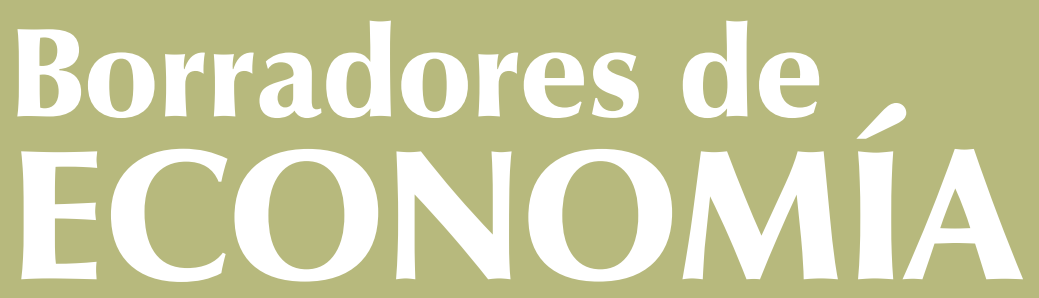

Por: Ana María Iregui Jesús Otero

Núm. 733
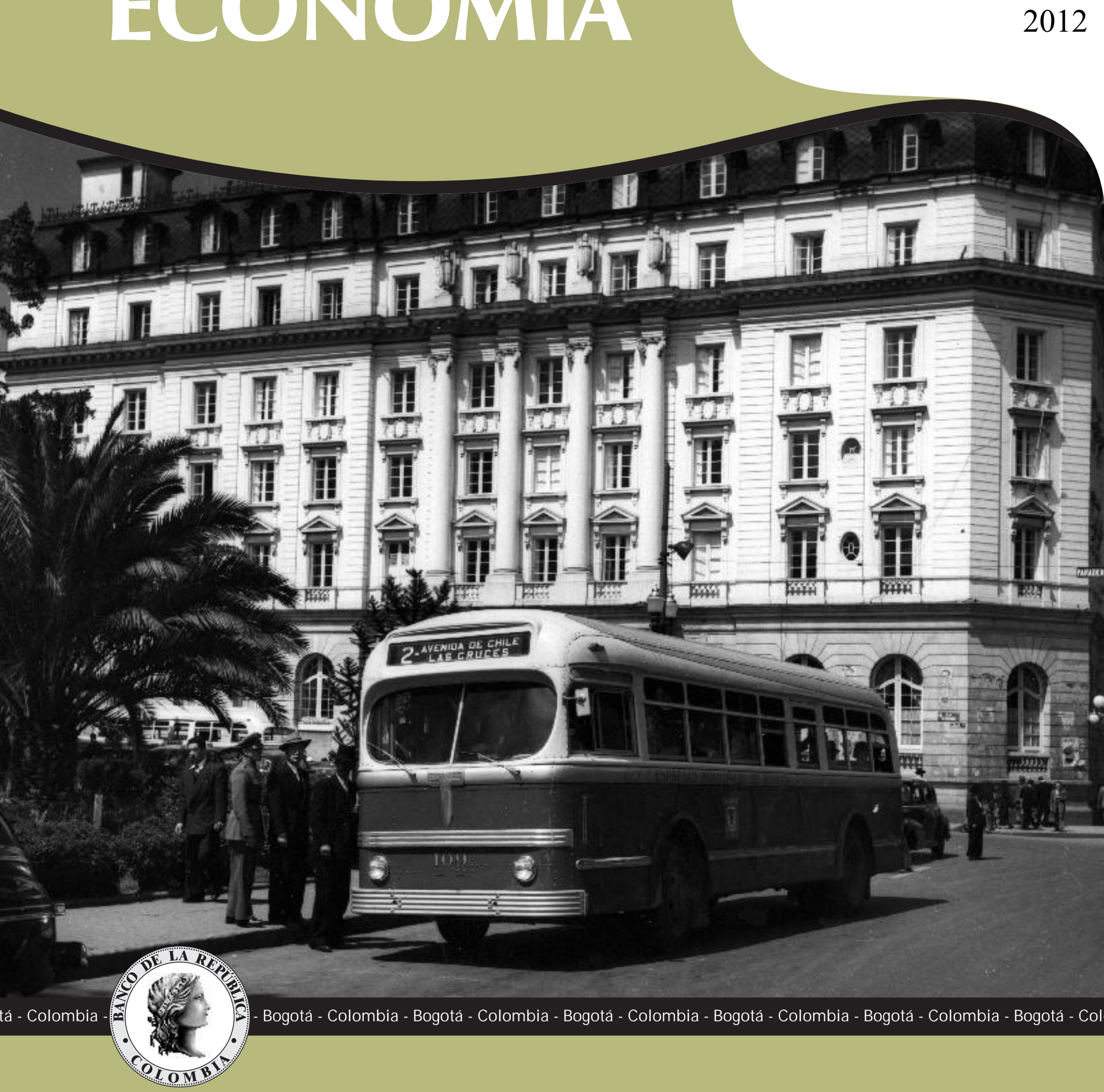


\title{
Testing the law of one price in retail banking: An analysis for Colombia using a pair-wise approach* $^{*}$
}

\author{
Ana María Iregui ${ }^{\dagger}$ \\ Unidad de Investigaciones \\ Banco de la República \\ Bogotá, Colombia
}

\author{
Jesús Otero \\ Facultad de Economía \\ Universidad del Rosario \\ Bogotá, Colombia
}

\begin{abstract}
We apply a pair-wise approach to test the law of one price for deposit (lending) rates in Colombia. We find that when banks are of different size deposit rates adjust quickly, suggesting a competitive environment. By contrast, lending rates adjust rapidly when banks are of similar size, supporting market segmentation.
\end{abstract}

JEL Classification: G21.

Keywords: Law of one price; retail interest rates; Colombia.

${ }^{*}$ We would like to thank Luis Eduardo Arango, Carlos Castro, Monica Giulietti, Luis Gutiérrez and Manuel Ramírez for their useful comments and suggestions. The opinions expressed herein are those of the authors and do not necessarily reflect the views of the Banco de la República or its Board of Directors.

${ }^{\dagger}$ E-mail: airegubo@banrep.gov.co

${ }^{\ddagger}$ E-mail: jesus.otero@urosario.edu.co 


\section{Introduction}

The law of one price (LOOP) is a key ingredient in several models in the economic literature. In its absolute version, this law asserts that in the presence of a competitive market structure, prices of identical products traded in different markets will be the same when expressed in the same currency. In practice, however, it has been argued that because of the presence of barriers to trade, such as imperfect information, transport costs and tariffs, the law cannot be expected to hold continuously. This has lead to the formulation of the relative version of the LOOP, according to which the law holds when price disparities are stationary; see e.g. Froot and Rogoff (1995).

Although the LOOP is one of the most widely tested economic hypotheses, few studies have investigated its validity in retail banking. Here the idea is that the same financial need, that is the desire to lend or the desire to borrow, can be met at the same price either continuously or not, depending on the version of the law; see e.g. Baele et al. (2004) and Akram et al. (2009). For instance, Martín-Oliver et al. (2007) use data on interest rates for loan and deposit operations from commercial and savings banks in Spain, and find that individual banks' idiosyncratic effects are the main determinant of the substantial and persistent deviations that are observed in the interest rates set by the banks. Akram et al. (2009) study the validity of the LOOP in international financial markets. This requires examining whether the domestic rate on deposits (loans) is the same as the foreign rate on deposits (loans), after the latter has been fully adjusted by exchange rate risk. According to these authors, the law does not hold continuously supporting the view that economic agents may be able to exploit arbitrage opportunities. Lastly, Affinito and Farabullini (2009) compare the interest rate differentials in twelve Euro-Area countries with those observed in twenty Italian regions, and find that banking integration is much higher in the latter.

This paper seeks to further our understanding of the LOOP, by examining its validity in the retail banking sector of Colombia. As seen above, existing literature concerning the LOOP in retail banking has been primarily concerned with developed 
countries, so that further research on this important topic for a developing economy such as Colombia appears fruitful. Colombia is an interesting case study because the country's financial system had historically been subjected, like in many other developing countries, to heavy regulations and restrictions. However, about two decades ago the government implemented a series of economy-wide reforms, with the purpose of modernising the economy and making it more competitive and efficient. ${ }^{1}$ Thus, the financial liberalisation reforms make the case for assessing the validity of the LOOP in retail banking. Indeed, if the LOOP holds for deposit (lending) interest rates, then there would be support for the view that the new institutional framework has led to a fully integrated market.

While unit root (stationarity) testing of price differentials has become a commonly used methodological approach to test for the relative version of the LOOP, it is well known that these tests applied to single series exhibit poor power properties. In recent years, panel unit root (stationarity) tests have been applied as a means of addressing the low statistical power associated to univariate methods; see e.g. Breitung and Pesaran (2008) for a survey of the literature. However, panel tests applied to the hypothesis of the LOOP are not exempt from an important deficiency, namely that the outcome of the tests may be sensitive to the selection of the benchmark price, that is the price with respect to which all other prices are being measured. In an attempt to overcome this deficiency, we use a pair-wise econometric approach proposed by Pesaran (2007). The idea behind this approach is that given data on, say, $N$ interest rates, we apply unit root tests on all $(N(N-1) / 2)$ differentials, and then compute the fraction of these differentials for which the unit root hypothesis is rejected. Pesaran shows that, although the underlying individual unit root tests are not cross-sectionally independent, under the null of non-convergence the fraction of rejections converges to the nominal size of the underlying unit root tests, denoted $\alpha$. The salient feature of our paper is that rather than confining our attention to this fraction of rejections, as in the Affinito and Farabullini (2009) analysis of the LOOP

\footnotetext{
${ }^{1}$ See Uribe and Vargas (2003) for a summary of the package of financial liberalisation reforms.
} 
in Euro-Area retail banking, we concentrate on the differentials for which the unit root hypothesis is rejected, and attempt to determine the factors that help explain the time it takes for deviations from the LOOP to adjust to equilibrium.

The plan of the paper is as follows. Section 2 describes the data set. Section 3 reports the results of the empirical analysis. Section 4 concludes.

\section{Data}

We employ retail interest rate data obtained from weekly surveys on deposits and loans reported by the banks to the Colombian Superintendency of Financial Institutions. The data are for deposit (lending) rates offered by $N=15$ banks, implying a total of 105 possible deposit (lending) rate differentials. In 2010, the assets of the fifteen banks under consideration amounted to almost the totality of the assets of the banking sector (i.e. about 99.5\%). The interest rate series are sampled weekly from May 2002 to February 2010, for a total of $T=406$ observations. The choice of banks included in the analysis is dictated by the need to assemble a consistent and balanced panel over the whole study period.

The deposit (lending) rates are computed over all maturities. Thus, the deposit rate of bank $i$ is the weighted average rate paid by the bank on 30-, 45-, 60-, 90-, 120-, 180-, 360-, and more than 360-day time deposits (CDTs), using the amount of deposits at each maturity as weight. In turn, the lending rate of bank $i$ is the weighted average rate charged on 1-, 3- and 5-year consumption loans, using the amount of loans at each maturity as weight. At this point, one might argue that aggregating over all maturities may serve to smooth fluctuations, and this might subsequently work in favour of finding support for the LOOP. For this reason, we also employ interest rate data at two representative maturities, namely the weighted average deposit rate paid on 180- and 360-day time deposits, and the weighted average lending rate charged on 1- and 3-year consumption loans. When describing our results the terms deposit and lending will refer to the average interest rates calculated over all maturities, unless specified otherwise. 


\section{$3 \quad$ Empirical analysis}

We begin by examining the discrepancies in deposit (lending) rates, for which we calculate the cross-sectional standard deviation across the fifteen banks under consideration, over the sample period. The results reveal a much smaller degree of dispersion in deposit than in lending rates, as in the former the range of variation of the cross-sectional standard deviation lies between 0.28 and 1.75 percentage points, while in the latter it varies between 1.71 and 5.58 percentage points. Strictly speaking these results do not support the absolute version of the LOOP, which would require the cross-sectional standard deviation to be equal to zero, although it has been closer to hold for deposit than for lending rates. These findings also suggest that while in the market for deposits there is limited scope for exploiting price differences, in the market for loans some sort of comparison of bank offers might prove profitable.

Turning to the relative version of the LOOP, Table 1 reports the percentage of rejections by the $\mathrm{ADF}$ and $\mathrm{ADF}_{\max }$ unit root tests of Dickey and Fuller (1979) and Leybourne (1995), respectively, based on all 105 interest rate differentials. The tests are performed at the $5 \%$ and $10 \%$ significance levels, a linear trend is included in the test regression if significant at the $5 \%$ level (using standard normal tables), and the optimal lag length is chosen using the Akaike information criterion (AIC), with $p_{\max }=2$ lags (results were similar when $p_{\max }=3,4$ ). As can be seen, in all cases the percentage of rejections exceeds the underlying size of the unit root tests. For instance, the ADF test applied to deposit rates leads to a rejection frequency of $89.5 \%$, while for lending rates the rejection frequency is higher, i.e. 98.1\%. For the $\mathrm{ADF}_{\text {max }}$ test the corresponding rejection frequencies at the $10 \%$ significance level are $94.3 \%$ and $90.5 \%$ for deposit and lending rates, respectively.

Thus far, we find strong support for the validity of adjustment towards the relative version of the LOOP for both deposit and lending rates in Colombia. At first sight, there does not seem to be a noticeable difference between deposit and lending rates as, in both cases, the fraction of stationary differentials is very large. However, a rather different and interesting picture emerges when one calculates the average 
mean lag of the deposit and lending rate differentials that are stationary. Indeed, for deposit rates the average mean lag is 1.95 weeks compared to 3.68 weeks for lending rates, suggesting that deposit rates converge to their equilibrium value at a much quicker rate than lending rates.

Next, we attempt to understand the factors that explain the speed of adjustment of deposit (lending) rates. To do this, we focus on the differentials that are stationary, based on the ADF test at the $10 \%$ significance level, and calculate the estimated halflife of a shock, denoted $h l_{i j}{ }^{2}$ Then, we examine the following factors as potential determinants of $h l_{i j}$.

First, we consider the size of bank $i$ relative to bank $j$, as measured by the absolute value of the difference of the logarithm of their total assets $(T A)$, that is $d t a_{i j}=\left|\log T A_{i}-\log T A_{j}\right|$. Here, a positive (negative) sign on the coefficient associated to $d t a_{i j}$ would indicate that adjustment is faster when banks are similar (different) in size. Second, we use a dummy variable $o w n_{i j}=1$ when banks $i$ and $j$ are owned by the same financial conglomerate (0 otherwise). A negative sign on the coefficient associated to this variable would indicate that adjustment is faster when two banks belong to the same financial conglomerate. Third, we introduce the dummy variable foreign $_{i j}=1$ when banks $i$ and $j$ are foreign ( 0 otherwise). A negative sign on the coefficient associated to this variable would indicate that interest rates adjust faster between banks that are foreignly owned. In such a case, there would be support for the view that foreign banks follow closely the actions of other non-domestic intermediaries. The resulting regression model is:

$$
h l_{i j}=\beta_{1}+\beta_{2} d t a_{i j}+\beta_{3} \text { own }_{i j}+\beta_{4} \text { foreign }_{i j}+\epsilon_{i j} .
$$

Notice that in equation (1) only two dummy variables are included even though there are four conditions. This is because in our sample there are no banks $i$ and $j$ that satisfy the conditions of being foreign and owned by the same financial conglomerate. Thus, the intercept term must be interpreted as the group against which

\footnotetext{
${ }^{2}$ The half-life is approximated using the formula $-\ln (2 /(1+\hat{\delta}))$, where $\hat{\delta}$ denotes the autoregressive coefficient in the corresponding ADF test regression; see Goldberg and Verboven (2005).
} 
comparisons are made, namely domestic banks that do not belong to the same financial conglomerate. ${ }^{3}$

Table 2 reports the results of estimating equation (1) by OLS (the model diagnostic tests in this table are generally satisfactory). The results suggest a markedly different behaviour between deposit and lending rates. Focusing first on deposit rates, the estimated coefficient on $d t a_{i j}$ is negative and significant, indicating rapid speed of adjustment when banks are of different size. This finding may be thought of as supporting the idea of small and large banks operating in a competitive market for deposits. The estimated coefficient on $o w n_{i j}$ is negative and significant, suggesting faster adjustment when banks belong to the same financial conglomerate; put another way, despite banks being different, the fact that they are part of the same conglomerate means that they may be thought of as acting as a single entity. Likewise, the estimated coefficient on foreign $n_{i j}$ is also negative and significant, indicating faster adjustment when the origin of two banks is foreign.

By contrast, when one looks at lending rates, the estimated coefficient on $d t a_{i j}$ is positive and significant (at the $5 \%$ level based on a one-sided test) suggesting that adjustment occurs quickly when banks are of similar size. In other words, it appears that competition in the lending market is stronger when institutions are similar in size. The estimated coefficient on foreign $_{i j}$ is positive and significant, indicating that adjustment is slower when banks are foreign. The fact that foreign banks adjust their lending rates more slowly may be viewed as evidence of loan market fragmentation (or that they serve different segments of the market). Lastly, the estimated coefficient on $o w n_{i j}$ is, once again, found to be negative and significant, reflecting the fact that adjustment in lending rates occurs more quickly when banks belong to the same financial conglomerate.

Table 2 also shows that similar findings are obtained when using the deposit rate

\footnotetext{
${ }^{3}$ In addition to total assets, we also considered other structural characteristics of the banking system such as total loans, total capital, the number of current and savings accounts, and the ratio of total loans to total assets. However, the inclusion of these additional explanatory variables in general yielded coefficients that did not turn out to be statistically different from zero, nor led to any substantial increase in the fit for these models.
} 
paid on 180- and 360-day time deposits, and the lending rate charged on 1- and 3-year consumption loans.

\section{Concluding remarks}

We investigate whether the law of one price holds among the interest rates set by Colombian banks. Instead of confining our attention to the analysis of the time series properties of $(N-1)$ interest rates relative to that of some reference bank, we consider all $(N(N-1) / 2)$ interest rate differentials. Applying this pair-wise approach to deposit and lending rates reveals strong support in favour of adjustments to the relative version of the law of one price, since the null hypothesis of a unit root is rejected in more than $85 \%$ of the cases. Thus, it appears that the financial liberalisation reforms of the early 1990s have led to integrated markets for deposits and loans. As for the speed at which interest rate differentials adjust to the law of one price, we uncover evidence of rapid adjustment in the market for deposits when banks are of different size, suggesting a competitive environment. In the market for loans, adjustment is quicker when banks are of similar size, supporting the view of market segmentation. We find evidence of faster adjustment when banks are owned by the same financial conglomerate, so that they may be thought of as operating as a single entity. Lastly, there is also evidence that deposit rates adjust quickly when banks are foreign. 


\section{References}

Affinito, M. and F. Farabullini (2009). Does the law of one price hold in EuroArea retail banking? an empirical analysis of interest rate differentials across the monetary union. International Journal of Central Banking 5, 5-37.

Akram, Q. F., D. Rime, and L. Sarno (2009). Does the law of one price hold in international financial markets? evidence from tick data. Journal of Banking and Finance 33, 1741-1754.

Baele, L., A. Ferrando, P. Hordahl, E. Krylova, and C. Monnet (2004). Measuring European finnancail integration. Oxford Review of Economic Policy 20, 96-112.

Breitung, J. and M. H. Pesaran (2008). Unit roots and cointegration in panels. In L. Mátyás and P. Sevestre (Eds.), The Econometrics of Panel Data, pp. 279-322. Berlin: Springer-Verlag.

Dickey, D. A. and W. A. Fuller (1979). Distribution of the estimators for autoregressive time series with a unit root. Journal of the American Statistical Association 74, $427-431$.

Froot, K. and K. Rogoff (1995). Perspectives on PPP and long-run real exchange rates. In G. M. Grossman and K. Rogoff (Eds.), Handbook of International Economics. Volume 3, pp. 1647-1688. Amsterdam: North Holland.

Goldberg, P. and F. Verboven (2005). Market integration and convergence to the law of one price: Evidence from the european car market. Journal of International Economics 65, 49-73.

Leybourne, S. (1995). Testing for unit roots using forward and reverse Dickey-Fuller regressions. Oxford Bulletin of Economics and Statistics 57, 559-571.

Martín-Oliver, A., V. Salas-Fumás, and J. Saurina (2007). A test of the law of one price in retail banking. Journal of Money, Credit and Banking 39, 2021-2040.

Pesaran, M. H. (2007). A pair-wise approach to testing for output and growth convergence. Journal of Econometrics 138, 312-355.

Uribe, J. D. and H. Vargas (2003). Financial reform, crisis and consolidation in Colombia. In P. L. V. der Haegen and J. Viñals (Eds.), Regional Integration in Europe and Latin America. Monetary and Financial Aspects, pp. 419-446. Aldershot: Ashgate. 
Table 1. Proportion of stationary interest rate differentials

\begin{tabular}{lcccc}
\hline \hline \multicolumn{2}{c}{ Deposit rates } & \multicolumn{2}{c}{ Lending rates } \\
Unit-root test & $180-$, 360-day & All maturities & 1-, 3-year & All maturities \\
\hline & & & & \\
$\mathrm{ADF}$ & & & & \\
$\alpha=0.10$ & $91.4 \%$ & $89.5 \%$ & $99.0 \%$ & $98.1 \%$ \\
$\alpha=0.05$ & $88.6 \%$ & $87.6 \%$ & $99.0 \%$ & $96.2 \%$ \\
& & & & \\
$\mathrm{ADF}_{\max }$ & & & & \\
$\alpha=0.10$ & $92.4 \%$ & $94.3 \%$ & $91.4 \%$ & $90.5 \%$ \\
$\alpha=0.05$ & $91.4 \%$ & $88.6 \%$ & $86.7 \%$ & $86.7 \%$ \\
\hline
\end{tabular}

Notes: The unit-root test regressions include linear trend if it is statistically significant at the $5 \%$, and the number of lags is selected using the Akaike information criterion with $p_{\max }=2$. The significance level of the unit root tests is $\alpha$.

Table 2. Determinants of the half-life of interest rate differentials

\begin{tabular}{|c|c|c|c|c|c|c|c|c|}
\hline & \multicolumn{4}{|c|}{ Deposit rate } & \multicolumn{4}{|c|}{ Lending rate } \\
\hline & \multicolumn{2}{|c|}{ 180-, 360-day } & \multicolumn{2}{|c|}{ All maturities } & \multicolumn{2}{|c|}{ 1-, 3-year } & \multicolumn{2}{|c|}{ All maturities } \\
\hline & Coeff. & (s.e.) & Coeff. & (s.e.) & Coeff. & (s.e.) & Coeff. & (s.e.) \\
\hline Intercept & 2.568 & $(0.362)$ & 2.565 & $(0.369)$ & 2.982 & $(0.282)$ & 3.046 & $(0.350)$ \\
\hline$d t a$ & -0.384 & $(0.204)$ & -0.549 & $(0.221)$ & 0.500 & $(0.308)$ & 0.693 & (0.398) \\
\hline own & -0.523 & $(0.384)$ & -0.816 & $(0.366)$ & -1.552 & $(0.527)$ & -1.663 & $(0.534)$ \\
\hline foreign & -0.550 & $(0.282)$ & -0.928 & $(0.244)$ & 1.319 & $(0.773)$ & 1.528 & $(0.656)$ \\
\hline Obs. & 96 & & 94 & & 104 & & 103 & \\
\hline$\hat{\sigma}$ & 1.886 & & 1.727 & & 1.795 & & 2.072 & \\
\hline Hetero & 1.658 & [0.798] & 3.296 & {$[0.510]$} & 6.972 & [0.137] & 8.264 & [0.082] \\
\hline Reset & 0.003 & {$[0.957]$} & 0.630 & {$[0.430]$} & 0.001 & [0.993] & 0.005 & {$[0.943]$} \\
\hline
\end{tabular}

Notes: $\hat{\sigma}$ is the equation standard error. Hetero is the $\chi^{2}$ version of the White Heteroskedasticity test of unknown form (without cross terms). Reset is the F version of the Ramsey regression specification error test. Numbers in [•] are the probability values of the diagnostic test statistics. 